得asyou

EGG 11265-1081

LABORATORY

UC-702

OPERATED FOR THE U.S.

DECEMBER 1994

\title{
AN AERIAL RADIOLOGICAL SURVEY OF THE NEUTRON PRODUCTS COMPANY AND SURROUNDING AREA
}

\author{
DICKERSON, MARYLAND
}

DATE OF SURVEY: NOVEMBER 1993

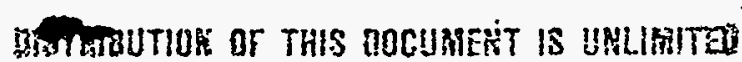




\section{DISCLAIMER}

This report was prepared as an account of work sponsored by an agency of the United States Government. Neither the United States Government nor any agency thereof, nor any of their employees, make any warranty, express or implied, or assumes any legal liability or responsibility for the accuracy, completeness, or usefulness of any information, apparatus, product, or process disclosed, or represents that its use would not infringe privately owned rights. Reference herein to any specific commercial product, process, or service by trade name, trademark, manufacturer, or otherwise does not necessarily constitute or imply its endorsement, recommendation, or favoring by the United States Government or any agency thereof. The views and opinions of authors expressed herein do not necessarily state or reflect those of the United States Government or any agency thereof. 


\section{DISCLAIMER}

Portions of this document may be illegible in electronic image products. Images are produced from the best available original document. 


\title{
AN AERIAL RADIOLOGICAL SURVEY OF THE NEUTRON PRODUCTS COMPANY AND SURROUNDING AREA
}

\author{
DICKERSON, MARYLAND
}

DATE OF SURVEY: NOVEMBER 1993

R. J. Vojtech

Project Scientist

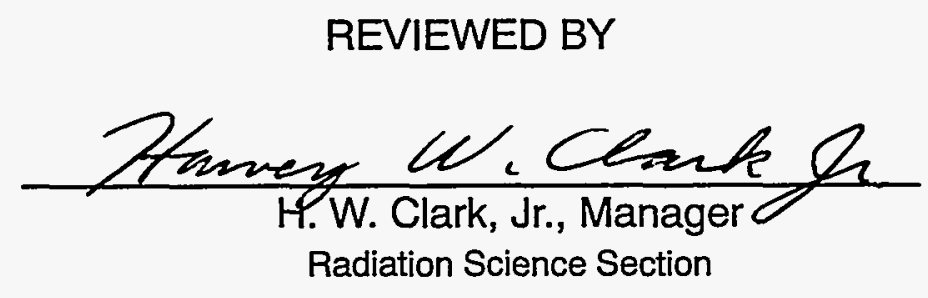

This Document is UNCLASSIFIED

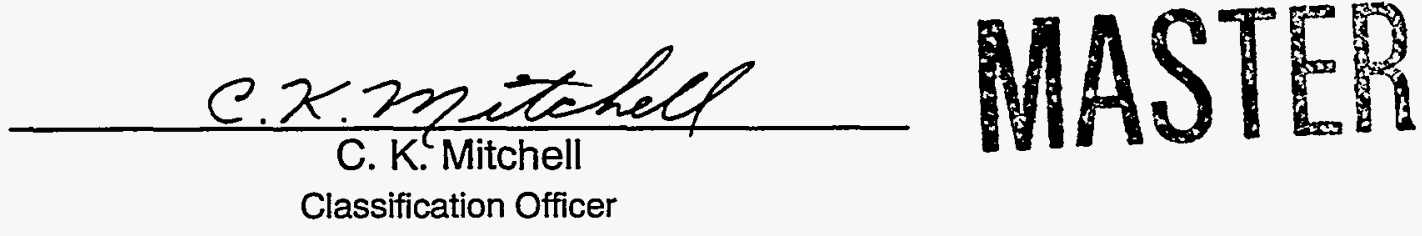

This work was performed by EG\&G/EM for the United States Department of Energy and the United States Nuclear Regulatory Commission under Contract Number DE-AC08-93NV11265. 


\begin{abstract}
An aerial radiological survey was conducted from November 1-10,1993, over the Neutron Products Company and neighboring areas. The company, located in Dickerson, Maryland, has two major operations involving the radioisotope cobalt-60 $\left({ }^{60} \mathrm{Co}\right)$-the manufacture of commercial ${ }^{60} \mathrm{Co}$ sources and the sterilization of medical products by exposure to radiation. The sterilization facility consists of two ${ }^{60} \mathrm{Co}$ sources with activities of approximately 500,000 and $1,500,000 \mathrm{Ci}$, respectively. The purpose of the aerial survey was to detect and document any anomalous gamma-emitting radionuclides in the environment which may have resulted from operations of the Neutron Products Company.

The survey covered two areas: the first was a 6.5- by 6.5-kilometer area centered over the Neutron Products facility; the second area was a 2- by 2.5-kilometer region surrounding a waste pumping station on Muddy Branch in Gaithersburg, Maryland. This site is approximately fifteen kilometers southeast of the Neutron Products facility and was included because sanitary and other liquid waste materials from the plant site are being disposed of at the pumping station.

Contour maps showing gamma radiation exposure rates at 1 meter above ground level, overlaid on an aerial photo of the area, were constructed from the data measured during the flights. The exposure rates measured within the survey regions were generally uniform and typical of rates resulting from natural background radiation. Only one area showed an enhanced exposure rate not attributable to natural background. This area, located directly over the Neutron Products facility, was analyzed and identified as ${ }^{60} \mathrm{Co}$, the radioisotope used in the irradiation and source production operations conducted at the Neutron Products Company. The measurements over the Muddy Branch area in Gaithersburg were typical of natural background radiation and showed no evidence of ${ }^{60} \mathrm{Co}$ or any other man-made radionuclide.
\end{abstract}




\section{CONTENTS}

Abstract

\section{Sections}

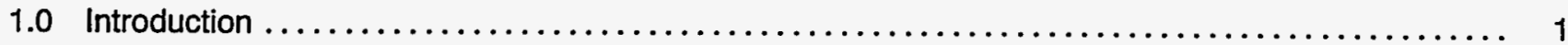

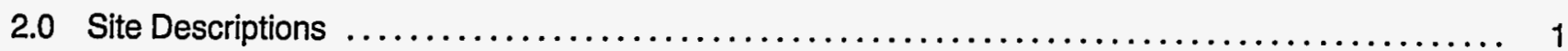

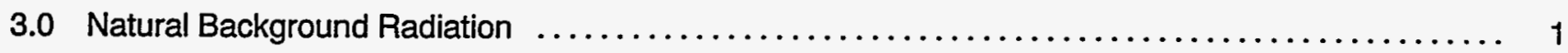

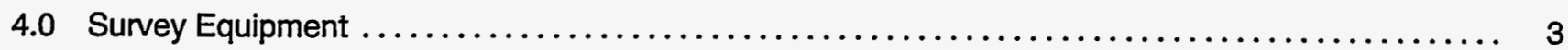

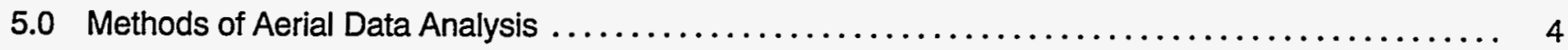

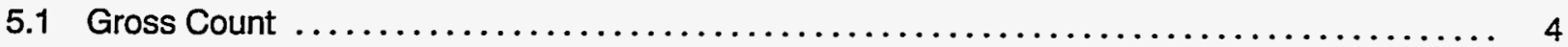

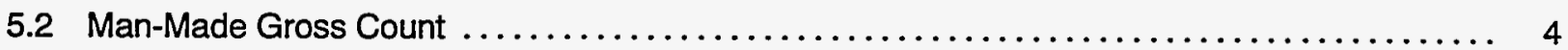

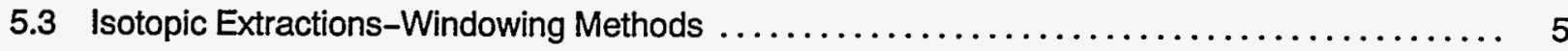

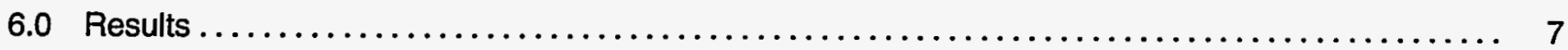

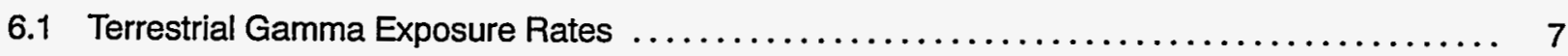

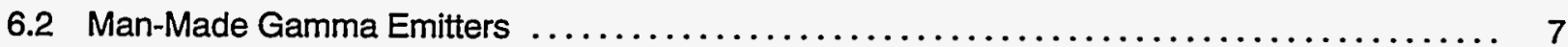

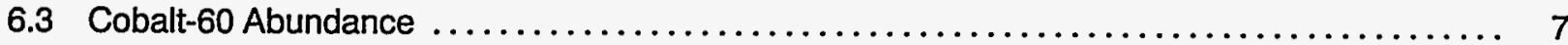

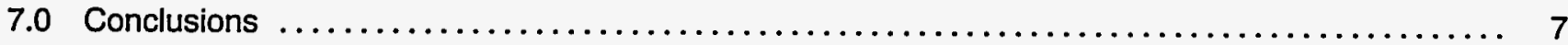

\section{Figures}

1 USGS Map Showing the Areas Surveyed for Anomalous Gamma Radiation ............... 2

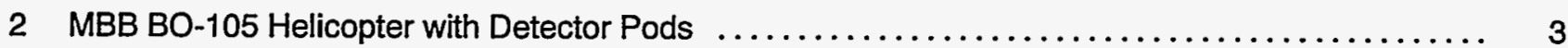

3 Gamma Ray Spectrum Showing the MMGC Energy Window $\ldots \ldots \ldots \ldots \ldots \ldots \ldots \ldots \ldots \ldots$

4 Gamma Ray Spectrum Showing the Two-Window Strip Energy Windows $\ldots \ldots \ldots \ldots \ldots \ldots \ldots .6$

5 Gamma Ray Spectrum Showing the Three-Window Strip Energy Windows $\ldots \ldots \ldots \ldots \ldots \ldots .7$

6 Isoradiation Contour Map Showing Total Terrestrial Activity in the Neutron Products Survey Area .. 8

7 Gamma Ray Energy Spectrum Showing Natural Terrestrial Background $\ldots \ldots \ldots \ldots \ldots \ldots \ldots .9$

8 Isoradiation Contour Map Showing Total Terrestrial Activity in the Muddy Branch Survey Area .... 10

9 Isoradiation Contour Map Showing ${ }^{60}$ Co Activity in the Neutron Products Survey Area ......... 11 
10 Gamma Ray Energy Spectrum Collected over the Neutron Products Facility.

\section{Appendix}

A Survey Parameters

References 


\subsection{INTRODUCTION}

An aerial radiological survey was conducted from November 1-10, 1993, over the Neutron Products Company and neighboring areas. The company, located in Dickerson, Maryland, is a source production and irradiation facility which uses cobalt-60 $\left({ }^{60} \mathrm{Co}\right)$ as its primary radioactive isotope. The purpose of the aerial survey was to detect and document any anomalous gamma-emitting radionuclides which may have been caused through the operation of the Neutron Products Company.

The aerial survey was performed by EG\&G Energy Measurements, Inc. (EG\&G/EM), which operates the Remote Sensing Laboratory for the United States Department of Energy Nevada Operations Office (DOE/NV). A primary mission of the Remote Sensing Laboratory is to maintain and manage the Aerial Measuring System (AMS). Since its inception in 1958, the AMS has continued a nation-wide effort to document baseline radiological conditions at nuclear energy-related sites of interest to the DOE. These sites include power plants, manufacturing and processing plants, and research laboratories utilizing nuclear materials.

The aerial survey of the Neutron Products Company was conducted at the request of the United States Nuclear Regulatory Commission and was sponsored by the DOE.

\subsection{SITE DESCRIPTIONS}

The Neutron Products Company is a manufacturing and irradiation facility located about thirty-five kilometers northwest of Washington, D.C., in Dickerson, Maryland. Two major operations are conducted at the site: the manufacture of commercial ${ }^{60} \mathrm{Co}$ sources and the sterilization of medical products by exposure to radiation. The sterilization facility consists of two ${ }^{60} \mathrm{Co}$ sources, with activities of approximately 500,000 and $1,500,000 \mathrm{Ci}$.

The AMS surveyed two areas near Dickerson, Maryland. The first region, shown in Figure 1, was a 6.5- $x$ 6.5-kilometer (4- $\times$ 4-mile) area centered over the Neutron Products facility. The terrain consists of gently rolling hills bordered by the Sugar Loaf Mountain to the north and the Monocacy and Potomac River drainage basins to the west. The area is rural, with farm fields and tree-covered hummocks. Several creeks are within the survey area, the most notable being the Little Monocacy River which flows near the Neutron Products Company.

Also shown in Figure 1 is the second area surveyed by the AMS, a $2-\times 2.5$-kilometer (1.25- $\times 1.5$-mile) area surrounding a waste pumping station on Muddy Branch in Gaithersburg, Maryland. It is located fifteen kilometers southeast of the Neutron Products facility. Sanitary and other liquid waste material from the Neutron Products Company are being disposed of at this station. ${ }^{1}$ This site is in a heavily developed urban area.

\subsection{NATURAL BACKGROUND RADIATION}

Natural background radiation originates from three primary sources: radioactive elements present in the soil, airborne radon, and cosmic rays of extraterrestrial origin. Natural terrestrial radiation levels depend upon the type of soil and bedrock immediately below and surrounding the point of measurement. In urban areas, these levels also depend on the nature of roadway and construction materials. Terrestrial gamma radiation originates primarily from the radioactive decay of elements naturally found in the soil and bedrock, namely, radioactive potassium and isotopes produced in the uranium and thorium decay chains. In general, local concentrations of these isotopes produce radiation levels at the surface typically ranging from 1 to $15 \mu \mathrm{R} / \mathrm{h}$ ( 9 to $130 \mathrm{mrem} / \mathrm{yr}$ ). ${ }^{2}$ Areas with high uranium and/or thorium concentrations may exhibit slightly higher levels.

One element of both the uranium and thorium radioactive decay chains is radon, a noble gas which can both diffuse through soil and travel through the air. Therefore, the level of airborne radiation due to radon and its daughter products depends on a variety of factors for a given location, including for example, meteorological conditions, mineral content of the soil, and soil permeability. Typically, airborne radiation from radon and its progeny contributes from 1 to 10 percent of the natural background radiation levels.

Cosmic rays interact with elements of the earth's atmosphere and soil, producing an additional source of gamma radiation. Radiation levels due to cosmic rays vary with altitude from $3.3 \mu \mathrm{R} / \mathrm{h}$ at sea level to 12 $\mu R / h$ at an elevation of 3,000 meters $\left(10,000\right.$ feet). ${ }^{3}$ The cosmic ray contribution in the survey area is estimated to be about $3.7 \mu \mathrm{R} / \mathrm{h}$. 


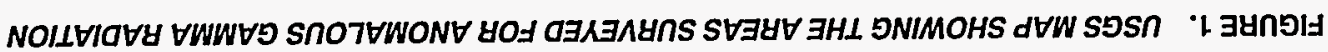

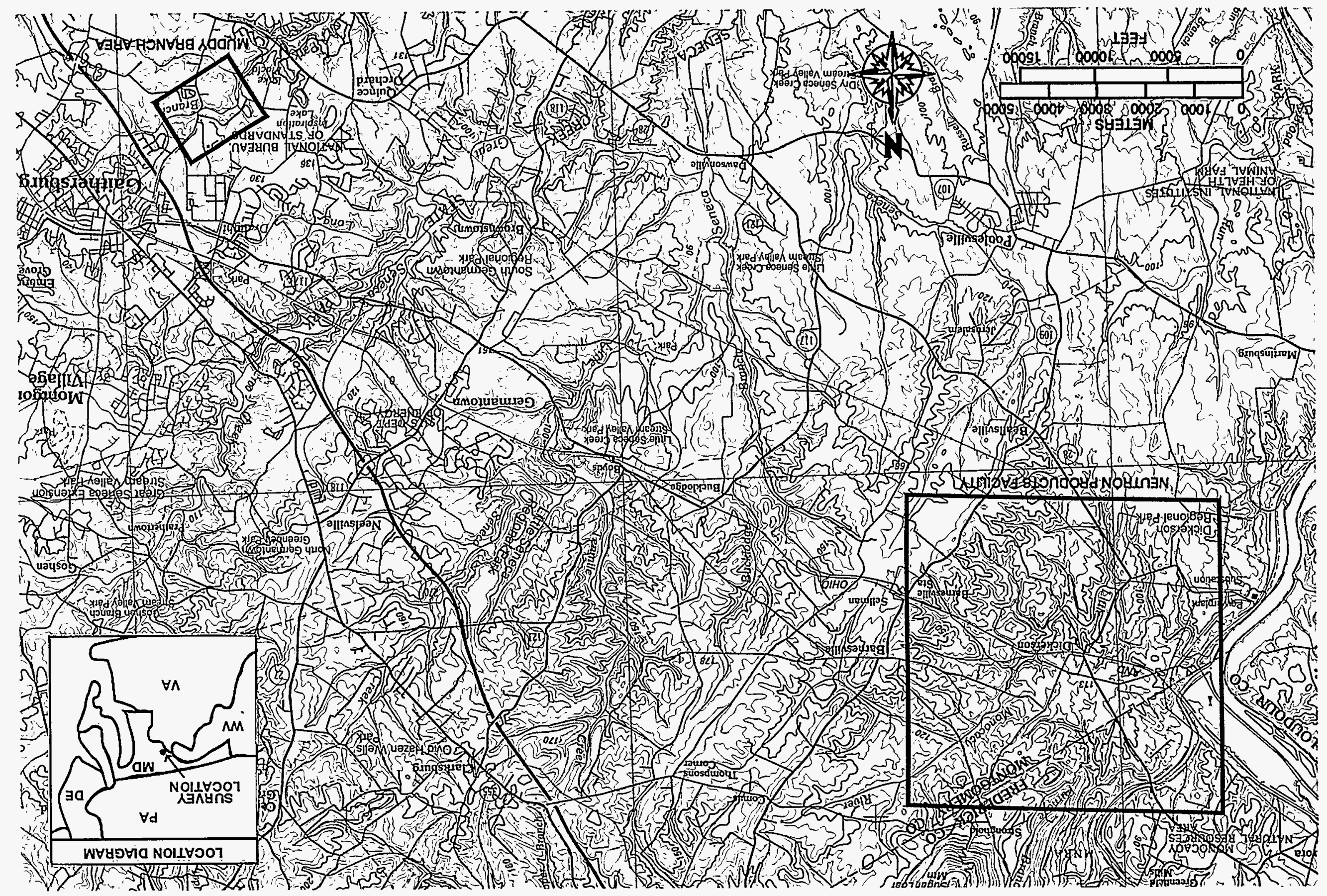




\subsection{SURVEY EQUIPMENT}

The Aerial Measuring System (AMS) used to perform the survey of the Neutron Products Company consists of a radiation detector and data acquisition computer system mounted aboard a high-performance helicopter. A fixed-base data analysis computer system, located at the Remote Sensing Laboratory facility at Andrews Air Force Base in Washington, D.C., supported the helicopter, reduced the spectral data, and presented the data as isopleth contour maps of exposure rates and isotopic intensities.

The Messerschmitt-Bolkow-Blohm (MBB) BO-105 helicopter shown in Figure 2 was used as the aerial platform. The helicopter carried a crew of two and the Radiation and Environmental Data Acquisition and Recorder Model IV (REDARIV) system. Two detector pods, each containing four $2-\times 4-\times 16$-inch (downlooking) and one 2- $\times 4-\times 4$-inch (uplooking) logtype thallium-activated sodium iodide $\mathrm{Nal}(\mathrm{Tl})$ scintillation detectors, were mounted on the side landing skids of the helicopter.

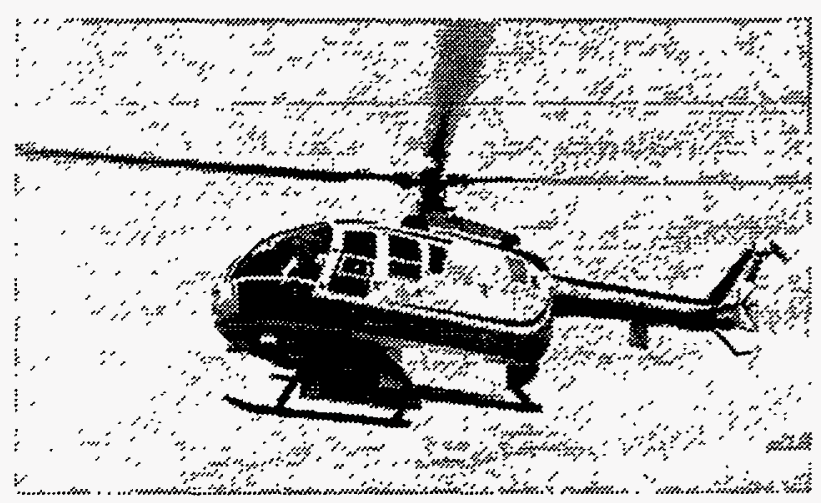

FIGURE 2. MBB B0-105 HELICOPTER WITH DETECTOR PODS

The voltage pulses produced through the interaction of gamma rays with the $\mathrm{Nal}(\mathrm{T} l)$ crystals were analyzed by analog-to-digital convertors (ADC) in the REDAR IV system. The REDAR IV is a multimicroprocessor-based data acquisition and real-time analysis system designed to operate in the severe environments associated with platforms such as helicopters, fixed-wing aircraft, and various ground-based vehicles. The system displays radiation and positional information in real time to the operator via video displays and multiple LED readouts. The gamma ray, helicopter-positioning, and weather data are recorded at one-second intervals on magnetic cartridge tapes for post-flight analysis on a ground-based minicomputer system.

Helicopter position was established using two systems: a Real-time Differential Global Positioning System (RDGPS) and a radar altimeter. The RDGPS is a ranging system which uses precise timing signals generated by a constellation of 24 satellites to determine the positions of the aircraft and a stationary ground unit placed at a known location in or near the survey area. The apparent position of the ground station is continually monitored and compared to its known location. A correction term is calculated and transmitted to the aircraft GPS unit, which applies the correction to its own position. This differential method removes position errors resulting from atmospheric conditions and $S A^{*}$ greatly increasing the accuracy of the position measurement. The RDGPS has the ability to locate the position of the aircraft to within \pm 5 meters, as opposed to \pm 100 meters achieved with a standard GPS. The radar altimeter determines the helicopter's altitude by measuring the round trip propagation time of a signal reflected off the ground. For altitudes up to 600 meters, the accuracy of this system is \pm 0.6 meter ( 2 feet) or $\pm 2 \%$, whichever is greater.

The position information from the RDGPS system and radar altimeter was simultaneously recorded along with the spectral information at one-second intervals on magnetic tape and directed to an aircraft steering indicator used to guide the aircraft along the predetermined flight lines. In aerial surveys, a flight line's altitude, line spacing, and speed are chosen to optimize the detector system's sensitivity to radionuclides and spatial resolution while maintaining a safe flight configuration. For the Neutron Products survey, the helicopter flew at an altitude of 46 meters ( 150 feet), a line spacing of 76 meters ( 250 feet), and a ground speed of 36 meters/second ( 70 knots).

A minicomputer-based system, the Radiation and Environmental Data Analyzer and Computer (REDAC) system, was used during the survey to evaluate the aerial data immediately following each survey flight. The REDAC system consists primarily of a

\footnotetext{
*The accuracy of the GPS is deliberately degraded by the Department of Defense. While in an operational mode called "Selective Availability" or "SA," a pseudo-random error is added to the satellite timing signals. SA is designed to deny hostile forces the precision positioning ability of the GPS.
} 
Data General 32-bit minicomputer system with 10 gigabytes of disk memory for data storage, two 8-mm tape drives for data transfer and archiving, and a 36-inch-wide carriage pen plotter for data contouring. Other peripheral devices include a laser printer and three graphics terminals with hardcopy units. This system has an extensive library of software routines available for complete data processing in the field.

\subsection{METHODS OF AERIAL DATA ANALYSIS}

The aerial radiation data generally consist of contributions from naturally-occurring radioisotopes, airborne radon, cosmic rays, and aircraft-related gamma radiation. For this survey, the major emphasis was placed on the detection of anomalous gamma radiation in the environment surrounding the Neutron Products Company. Isopleth maps were produced by processing the data using the extraction methods discussed below.

\subsection{Gross Count}

The gross count method is based on the integral counting rate in that portion of the gamma spectrum between 38 and $3,026 \mathrm{keV}$ :

$$
C R_{G C}=\sum_{E=38 \mathrm{keV}}^{3026 \mathrm{keV}} S(E)
$$

where $C R_{G C}$ is the gross counting rate, $E$ is the photon energy in keV, and $S(E)$ is the energy spectrum containing the number of gamma rays collected at the given energy $E$ per unit time. The gross counting rate, measured in counts per second at survey altitude, was converted to an exposure rate in $\mu R / h$ at a height of 1 meter above ground level (AGL) by the application of a conversion factor determined from the documented test line in Calvert County, Maryland. ${ }^{4}$ The conversion equation used is:

$$
E R=\left(\frac{C R_{G C}-C R_{B K G}}{1250}\right) e^{a A}
$$

where $E R$ is the $\mu \mathrm{R} / \mathrm{h}$ exposure rate extrapolated to 1 meter AGL and $C R_{G C}$ is the gross counting rate in counts/second at altitude $A$ (meters). The background counting rate, $C R_{B K G}$, attributed to cosmic rays, airborne radon, and aircraft-related gamma radiation, was determined by acquiring data at several altitudes over the survey area test line. The attenuation coefficient $\alpha$ in the exponential term of Equation 2 represents the attenuation of the terrestrial background by the atmosphere's air mass and was determined empirically for the aerial system at the survey site by taking data at different altitudes ranging from 46 to 300 meters (150-1,000 feet) over the survey area test lines. The value measured for the aerial system was:

$$
a=0.00634 m^{-1}
$$

At the 46-meter survey altitude, Equation 2 now becomes

$$
E R=\left(\frac{C R_{G C}-C R_{B K G}}{933}\right) e^{a(A-46)}
$$

where $A$ is the survey altitude in meters as measured by the aircraft's radar altimeter. These conversions assume a uniformly distributed source covering an area which is large when compared with the detector's field of view (an area with a diameter of approximately 100 meters at the altitude of 46 meters). Exposure rate values could be one to two orders of magnitude higher for a localized point source since the AMS averages all sources over a comparatively large area. The gross counting rate sum includes all naturally-occurring gamma rays from potassium, uranium, thorium, and their decay products, as well as contributions from airborne radon, cosmic rays, aircraft equipment, and man-made radionuclides. The background counting rate sum includes only contributions from airborne radon, cosmic rays, and aircraft equipment.

\subsection{Man-Made Gross Count}

Anomalous or nonnaturally-occurring gamma ray sources can often be found from increases in the gross counting rates. However, subtle anomalies are often difficult to find using the gross counting rate in areas where the natural radiation background varies due to geologic or ground cover changes. For example, the survey area's natural background (including a cosmic ray contribution of $3.7 \mu \mathrm{R} / \mathrm{h}$ ) was found to vary from 7 to $11 \mu R / h$ by moving several meters from 
woodlands to a developed area. Differential energy methods can be used to increase the sensitivity of the AMS to gamma ray emitters.

A man-made gross count (MMGC) algorithm has been designed to sense the presence of changes in spectral shapes using differential energy methods. This algorithm takes advantage of the fact that while background radiation levels often vary by a factor of two or more within a survey area, background spectral shapes remain essentially constant. More specifically, the ratio of natural components in any two integral sections (windows) of the energy spectrum will remain nearly constant in any given area:

$$
\frac{\sum_{E=a}^{b} S(E)}{\sum_{E=c}^{d} S(E)} \approx K=\text { Constant }
$$

where $S(E)$ is the energy spectrum, $E$ is the photon energy in $\mathrm{keV}$, and $a-d$ are energy values where $a<b \leq c<d$. An example of this is given in Figure 3 , which shows typical natural background and ${ }^{60} \mathrm{Co}$ spectra collected by a Nal(Tl) detector. In the energy region above $1,400 \mathrm{keV}$, both spectra are nearly identical. In the energy region below $1,400 \mathrm{keV}$, the additional photons from the ${ }^{60} \mathrm{Co}$ source result in a much larger gross counting rate. The $1,400-\mathrm{keV}$ value, which separates the spectrum into low and high energy regions was chosen to lie between the ${ }^{60} \mathrm{Co}$ $1,333 \mathrm{keV}$ peak and the potassium- $40\left({ }^{40} \mathrm{~K}\right)$ peak at $1,460 \mathrm{keV}$.

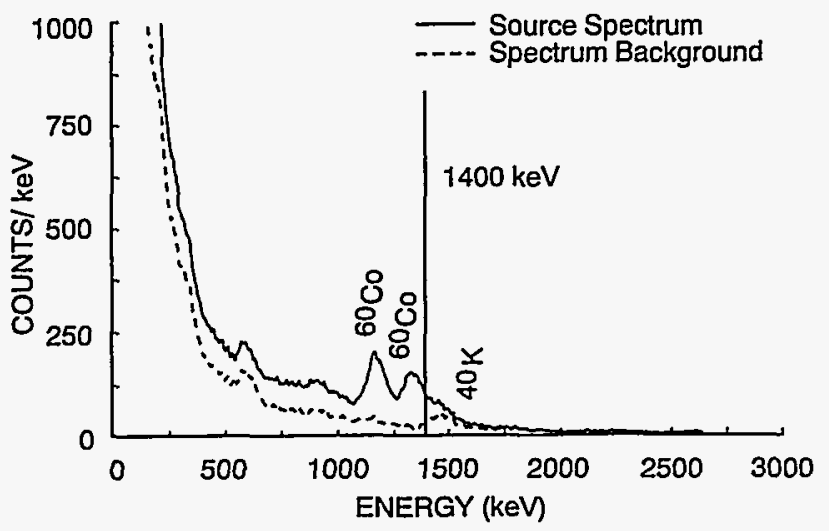

FIGURE 3. GAMMA RAY SPECTRUM SHOWING THE MMGC ENERGY WINDOW
In practice, a value of the constant $K$ defined in Equation 5 is obtained from the natural terrestrial background of the survey area:

$$
K \equiv \frac{\sum_{E=a}^{b} S_{B K G}(E)}{\sum_{E=c}^{d} S_{B K G}(E)}
$$

where $S_{B K G}(E)$ is an energy spectrum typical of the area's natural background. This allows a comparison of low-energy to high-energy windows to be made by:

$$
C R_{M M G C}=\sum_{E=a}^{b} S(E)-K \sum_{E=c}^{d} S(E)
$$

where $C R_{M M G C}$ is the net counting rate from anomalous gamma rays. In general, $C R_{M M G C}$ will vary about zero and become significantly positive in the presence of excess numbers of gamma rays with energies between $a$ and $b$.

For the Neutron Products survey, the value of the constant $K$ in Equation 6 was determined and Equation 7 was applied to the data using the energy values:

$$
\begin{aligned}
a & =38 \mathrm{keV} \\
b=c & =1394 \mathrm{keV} \\
d & =3026 \mathrm{keV}
\end{aligned}
$$

Note that an energy value of $1,394 \mathrm{keV}$ was chosen as the dividing point between low and high energy regions. This value was used instead of the $1,400 \mathrm{keV}$ discussed earlier for computational reasons.

The MMGC algorithm is designed to respond to a wide range of nuclides and, therefore, is quite general in nature. Its sensitivity to specific nuclides is less than optimal. The next section describes more sensitive algorithms for the detection of specific nuclides.

\subsection{Isotopic Extractions-Windowing Methods}

The determination of an individual isotope's contribution to the gross exposure rate requires an algorithm 
that can identify a specific photopeak's counting rate. The simplest of these algorithms are the two- and three-window strips. Although gamma rays emitted from nuclei have discrete, well-defined energies, the detector and electronic systems used in the measurements have energy resolutions which broaden the photopeak. Typically, monoenergetic gamma rays with energy $E$ completely collected by the detector will be distributed in a Gaussian-shaped peak within the energy "window" $E_{-} \leq E \leq E_{+}$. The energies $E_{-}$and $E_{+}$, defining the lower and upper energy window limits, are given by:

$$
E_{ \pm}=E \pm \Delta E
$$

where $\Delta E$ is defined as:

$$
\Delta E=3 \sigma=\left(\frac{3}{2.354}\right) F W H M
$$

with $\sigma$ representing the standard deviation of the Gaussian distribution and FWHM representing the full-width half-maximum detector resolution as determined by laboratory measurements. This $3 \sigma$ value ensures that more than $99.7 \%$ of the total photopeak counts are contained within the window.

The two-window stripping method assumes that the photon counting rate from a specific isotope can be determined from the sum of counts in the energy window minus a scaled background contribution. An example of this is given in Figure 4, which shows typical source (labeled $A$ ) and background $(B)$ windows used to extract the photopeak. The background-corrected photopeak counting rate, $C R_{W}$, is given by:

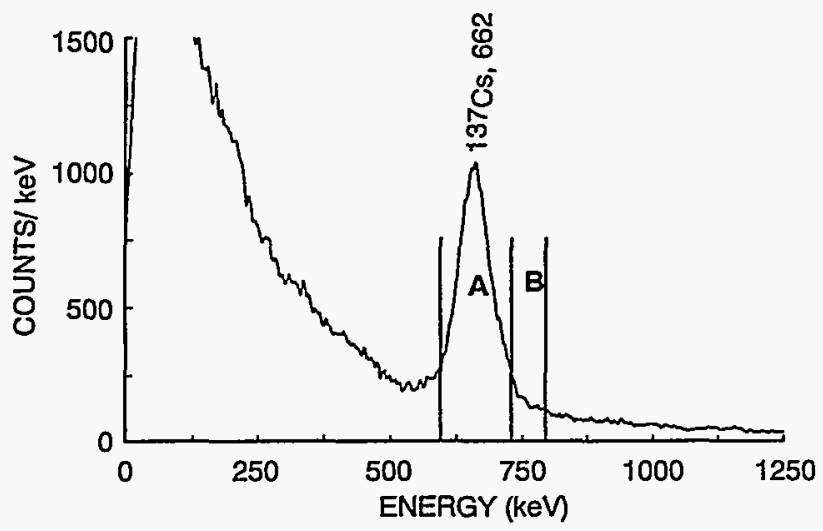

FIGURE 4. GAMMA RAY SPECTRUM SHOWING THE TWO-WINDOW STRIP ENERGY WINDOWS

$$
C R_{W} \equiv \sum_{E=a}^{b} S(E)-K \sum_{E=c}^{d} S(E)
$$

The scaling constant $K$ is:

$$
K=\frac{\sum_{E=a}^{b} S_{B K G}(E)}{\sum_{E=c}^{d} S_{B K G}(E)}
$$

Note that, except for differences in the choice of the limits $a-d, C R_{W}$ is identical in form to the $C R_{M M G C}$ defined in Equation 7. Ideally, the choice of the $a$ and $b$ limits for Equation 11 would be the energy limits $E_{-}$ and $E_{+}$. However, in practice it is often necessary to adjust the values of $a$ and $b$ to avoid interference from other contributing isotopes. For example, the cesium-137 ( $\left.{ }^{137} \mathrm{Cs}\right) 662-\mathrm{keV}$ photopeak falls within the window of the bismuth-214 $\left({ }^{214} \mathrm{Bi}\right) 609-\mathrm{keV}$ photopeak. The background limits $c$ and $d$ are chosen in a region containing only natural background radiation.

Although the two-window stripping method is highly sensitive, it does not have the ability to remove the contributions from other sources that were not present in the background data from which $K$ was derived. Therefore, a three-window stripping algorithm has been developed in which the background-corrected photopeak counting rate is defined as:

$$
C R_{W}=\sum_{E=a}^{b} S(E)-K\left[\sum_{E=c}^{d} S(E)+\sum_{E=e}^{f} S(E)\right]
$$

with the scaling constant $K$ given by:

$$
K \equiv \frac{\sum_{E=a}^{b} S_{B K G}(E)}{\sum_{E=c}^{d} S_{B K G}(E)+\sum_{E=e}^{f} S_{B K G}(E)}
$$

As with the two-window strip, the limits $a$ and $b$ represent the energy window limits about the photopeak. 
The limits $c-f$ represent the energy limits of the two "background" windows. Figure 5 shows an example of a typical three-window setup. The photopeak window is designated as $A$, while the background windows are given by $\mathbf{B}$ and $\mathbf{B}^{\prime}$.

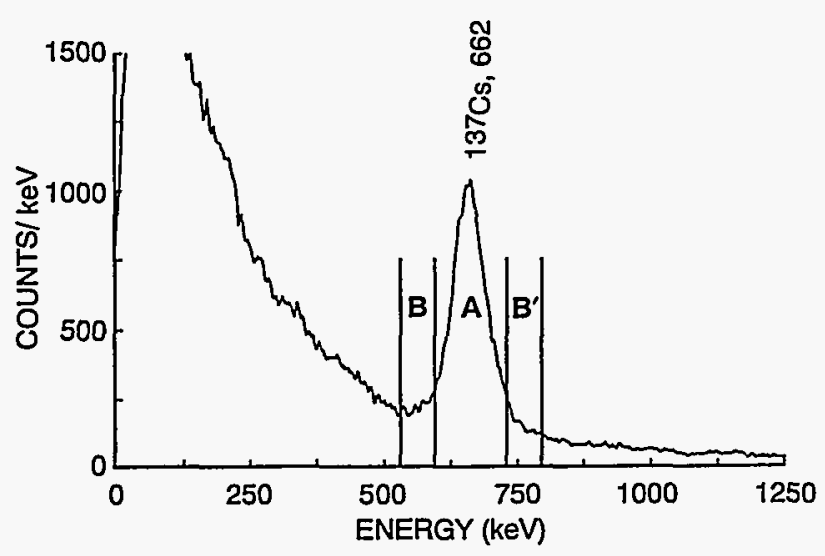

FIGURE 5. GAMMA RAY SPECTRUM SHOWING THE THREE-WINDOW STRIP ENERGY WINDOWS

\subsection{RESULTS}

\subsection{Terrestrial Gamma Exposure Rates}

The terrestrial gamma exposure rates within the Neutron Products survey area are shown in the form of a contour map in Figure 6. The levels shown in the contours include an estimated cosmic ray contribution of 3.7 $\mu \mathrm{R} / \mathrm{h}$ at 1 meter $\mathrm{AGL}$. The highly variable airborne radon component (about $0.2 \mu \mathrm{R} / \mathrm{h}$ ) is not included.

Over most of the survey area, the exposure rates shown represent normal fluctuations in the natural background due to varying concentrations of ${ }^{40} \mathrm{~K}$ and uranium and thorium daughter products in building and roadway materials and the soil. These levels typically range from 5-7 $\mu \mathrm{R} / \mathrm{h}$ over the marsh areas located in the northwestern region of the survey area to $11-13 \mu \mathrm{R} / \mathrm{h}$ over rocky areas located on the higher elevations to the east. The land area in the survey region appeared to have a uniform background activity from 7-11 $\mu \mathrm{R} / \mathrm{h}$. A gamma ray energy spectrum typical of the natural radiation background in the survey region is shown in Figure 7.

Exposure rates exceeding $1,300 \mu R / h$ were measured directly over the Neutron Products facility. These values could be one to two orders of magnitude higher for a localized point source since the AMS averages all sources over a comparatively large area.

The terrestrial gamma exposure rates within the Muddy Branch area are shown in Figure 8. These radiation levels shown are typical of natural background activity.

\subsection{Man-Made Gamma Emitters}

The MMGC algorithm presented in Equation 7 was used to search the aerial data for man-made emitters. For the Neutron Products facility survey area, no manmade radioisotopes were detected in the environment at distances greater than 300 meters $(1,000$ feet) from the Neutron Products buildings. High gamma ray counting rates were encountered directly over the facility. The contour plot produced by the MMGC algorithm is not shown because it is nearly identical to the ${ }^{60} \mathrm{Co}$ contour in Figure 9.

The MMGC algorithm search performed over the Muddy Branch survey area detected no anomalous gamma radiation.

\subsection{Cobalt-60 Abundance}

The windowing methods discussed in Section 5.3 were used to search both survey regions for the presence of ${ }^{60} \mathrm{Co}$. The data contours produced in the area surrounding the Neutron Products facility are displayed in Figure 9. These contours show the presence of ${ }^{60} \mathrm{Co}$ only in the immediate area of the Neutron Products Company facility. No ${ }^{60} \mathrm{Co}$ was detected at any distance greater than 300 meters ( 1,000 feet) from the center of the facility. A gamma ray energy spectrum collected over the plant is shown in Figure 10.

The ${ }^{60} \mathrm{Co}$ isotope search performed over the Muddy Branch region found no evidence of ${ }^{60} \mathrm{Co}$ within the survey area.

\subsection{CONCLUSIONS}

An aerial radiological survey was conducted from November 1-10, 1993, over the Neutron Products Company and neighboring areas. The purpose of the aerial survey was to detect and document any anomalous gamma-emitting radionuclides in the environment which may have been caused by operations at 


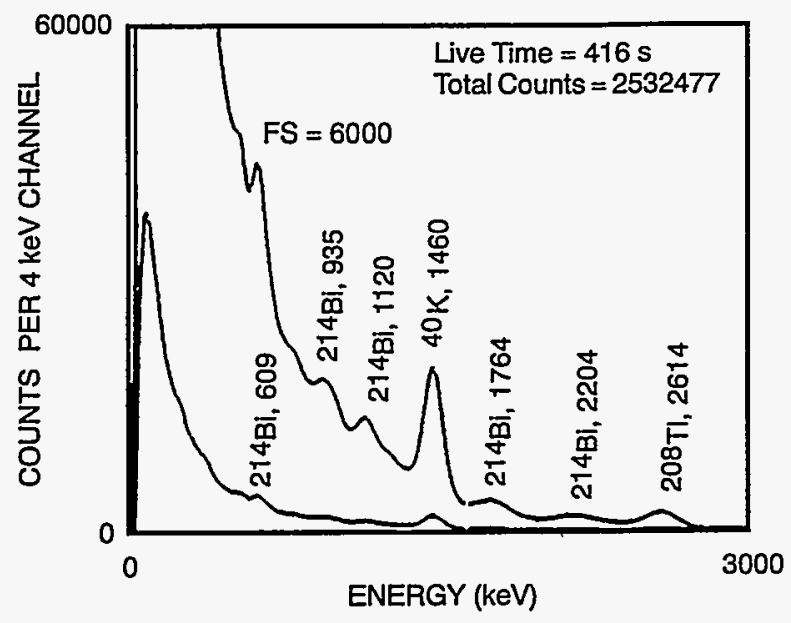

FIGURE 7. GAMMA RAY ENERGY SPECTRUM SHOWING NATURAL TERRESTRIAL BACKGROUND the Neutron Products Company. The exposure rates measured within the survey regions were generally uniform and typical of rates resulting from natural background radiation. Only one area which was measured showed an enhanced exposure rate not attributable to the natural background. This area, located directly over the Neutron Products facility, was analyzed and the additional radiation was found to be caused by ${ }^{60} \mathrm{Co}$, the radioisotope used in the irradiation and source production operations conducted at the Neutron Products Company. The measurements over the Muddy Branch area in Gaithersburg, Maryland, were typical of natural background radiation and showed no evidence of ${ }^{60} \mathrm{Co}$ or any other man-made radionuclide. 

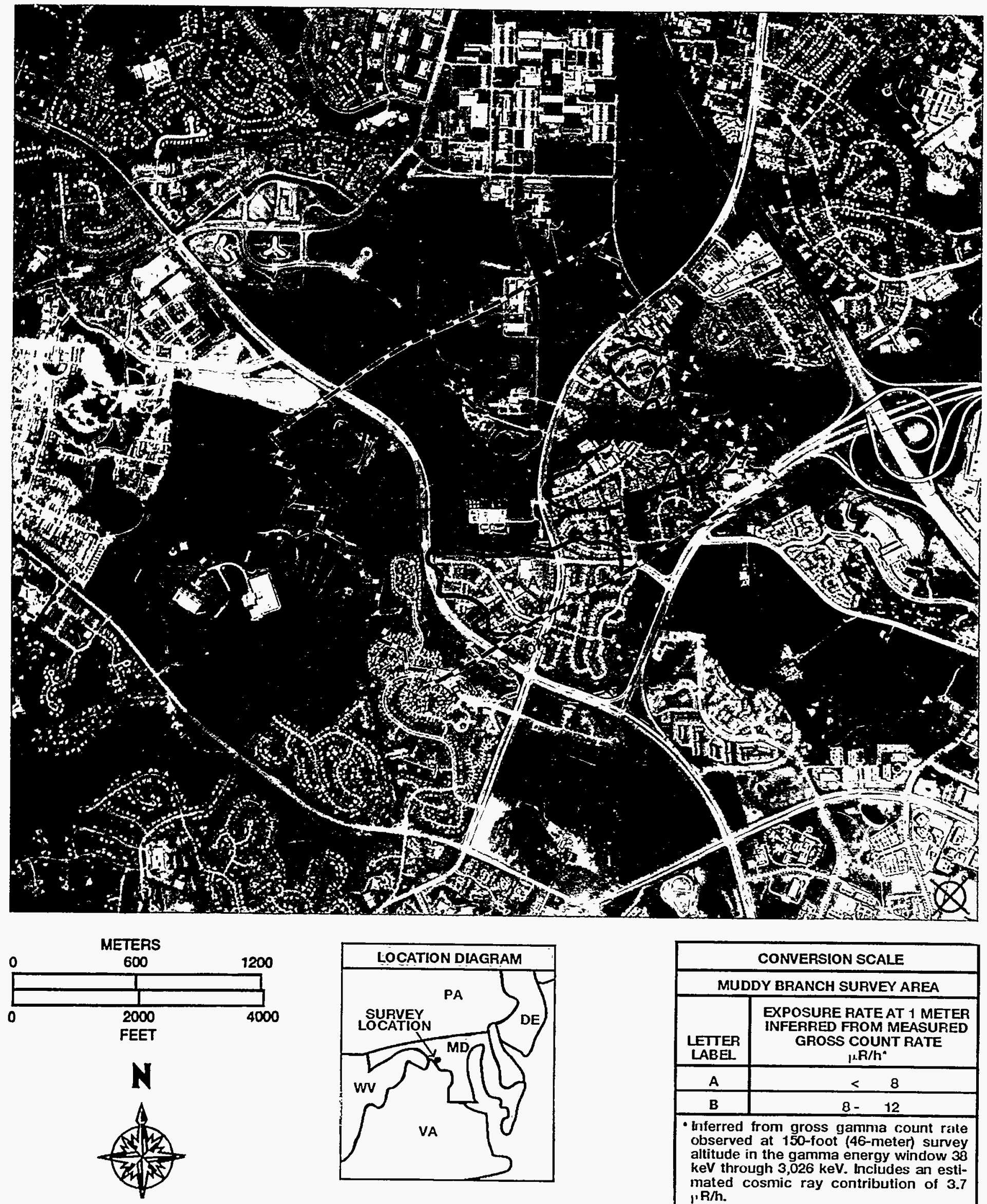

\begin{tabular}{|c|c|c|}
\hline \multicolumn{3}{|c|}{ CONVERSION SCALE } \\
\hline \multicolumn{3}{|c|}{ MUDDY BRANCH SURVEY AREA } \\
\hline $\begin{array}{c}\text { LETTER } \\
\text { LABEL } \\
\end{array}$ & $\begin{array}{r}\text { EXPOSURE RA } \\
\text { INFERRED FR } \\
\text { GROSS C } \\
\end{array}$ & $\begin{array}{l}\text { AT } 1 \text { METER } \\
\text { MEASURED } \\
\text { NT RATE }\end{array}$ \\
\hline A & $<$ & 8 \\
\hline B & $8-$ & 12 \\
\hline \multicolumn{3}{|c|}{$\begin{array}{l}\text { - Inferred from gross gamma count rate } \\
\text { observed at } 150 \text {-foot (46-meter) survey } \\
\text { altitude in the gamma energy window } 38 \\
k e V \text { through } 3,026 \mathrm{keV} \text {. Includes an esti- } \\
\text { mated cosmic ray contribution of } 3.7 \\
\text { f, R/h. }\end{array}$} \\
\hline
\end{tabular}

FIGURE 8. ISORADIATION CONTOUR MAP SHOWING TOTAL TERRESTRIAL ACTIVITY IN THE MUDDY BRANCH SURVEY AREA 


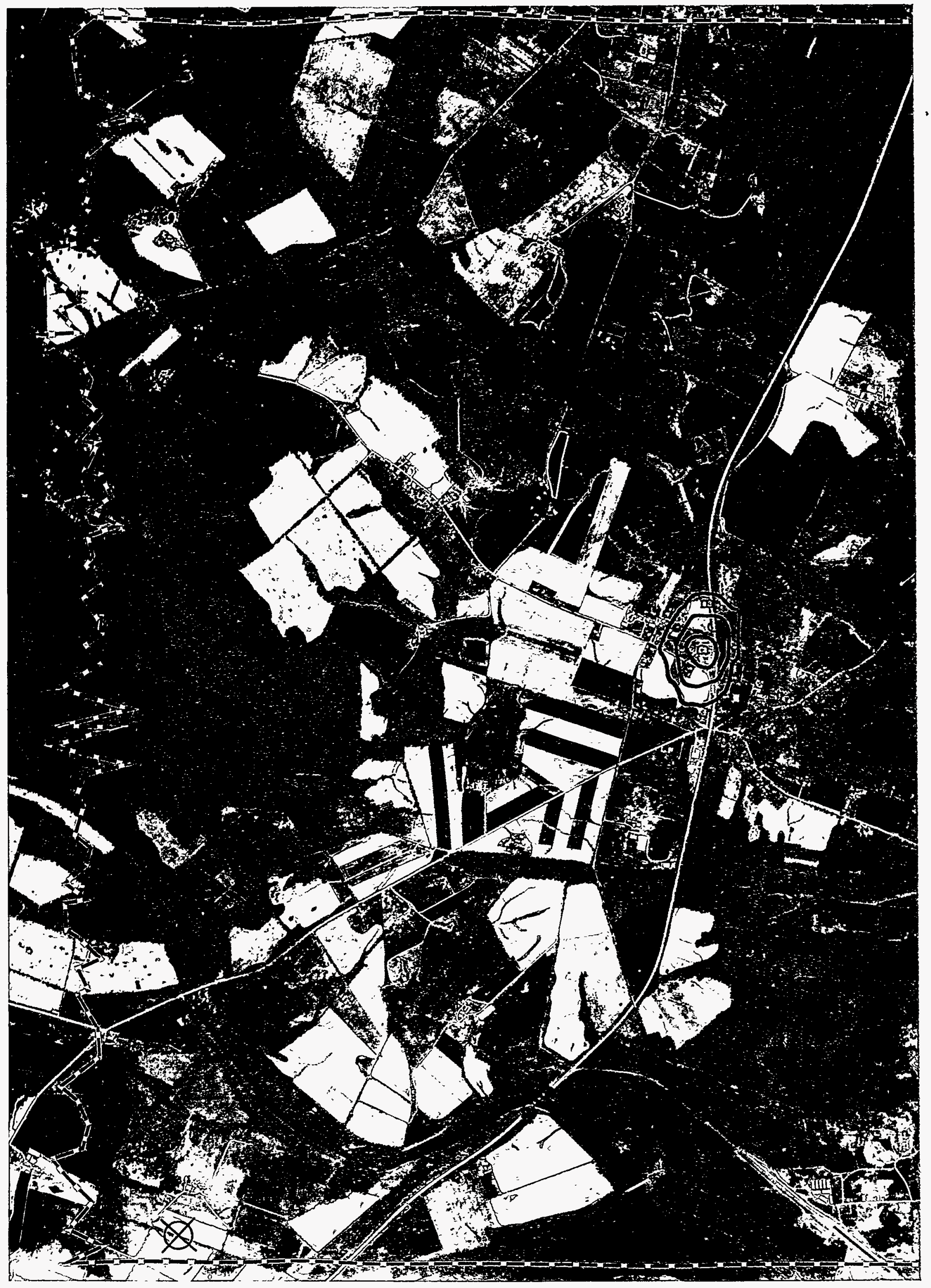




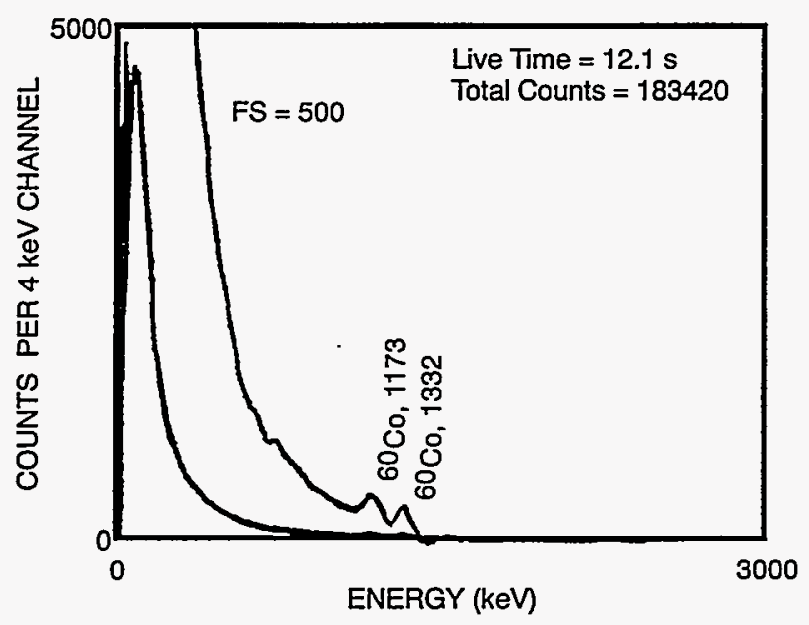

FIGURE 10. GAMMA RAY ENERGY SPECTRUM COLLECTED OVER THE NEUTRON PRODUCTS FACILITY 


\section{APPENDIX A}

\section{SURVEY PARAMETERS}

Survey Site:

Survey Location:

Survey Areas:

Survey Date:

Average Ground Speed

Survey Altitude:

Line Spacing:

Line Direction:

Number of Lines:

Detector Array:

Acquisition System:

Aircraft:

Project Scientist

Data Processing:
Neutron Products Company

Dickerson, Maryland

$39^{\circ} 13^{\prime} 20^{\prime \prime} \mathrm{N} \quad 77^{\circ} 25^{\prime} 18^{\prime \prime} \mathrm{W}$

Neutron Products: $42 \mathrm{~km}^{2}\left(16.5 \mathrm{mi}^{2}\right)$

Muddy Branch: $5 \mathrm{~km}^{2}\left(2 \mathrm{mi}^{2}\right)$

November 1-10, 1993

$36 \mathrm{~m} / \mathrm{s}$ (70 knots)

$46 \mathrm{~m}(150 \mathrm{ft})$

$76 \mathrm{~m}(250 \mathrm{ft})$

North/South

48

Eight $2-\times 4-\times 16$-in Nal $(\mathrm{Tl})$ detectors Two 2- $\times 4-\times 4$-in $\mathrm{Nal}(\mathrm{Tl})$ detectors

REDAR IV

MBB BO-105 helicopter (Tail \#N60EG)

R. Vojtech

Cobalt-60 Energy Window: 1,094-1,394

Man-Made Energy Window: $38-1,394 \mathrm{keV}$

Gross Count Energy Window: $38-3,026 \mathrm{keV}$

Conversion Factors: $933 \mathrm{cps} /(\mu \mathrm{R} / \mathrm{h})$ at $46 \mathrm{~m}$

Cosmic Ray Contribution: $3.7 \mu \mathrm{R} / \mathrm{h}$ 


\section{REFERENCES}

1. Norelius, C. Private communication, NRC Region I, 1993.

2. Lindeken, C.L., K.R. Peterson, D.E. Jones, R.E. McMillen. "Geographical Variations in Environmental Radiation Backgrounds in the United States," Proceedings of the Second International Symposium on the Natural Radiation Environment, 7-11 August 1972, Houston, Texas. National Technical Information Service, United States Department of Commerce, Springfield, Virginia, 1972, pp 317-332.

3. Klement, A.W., C.R. Miller, R.P. Min, B. Sherlen. Estimate of Ionizing Radiation Doses in the United States 1960-2000, U.S. EPA Report ORP/CSD72-1. EPA, Washington, D.C., 1972.

4. Mohr, R.A. Ground Truth Measurements at the Calvert County, Maryland Test Line, Report No. EGG-10282-2066. EG\&G/EM, Santa Barbara, California, 1985. 
$\mathrm{NRC} / \mathrm{HQ}$

E. D. Weinstein

(1)

NRC/REGION I

P. D. Kaufman

(16)

\section{DOE/DP}

L. E. Gordon-Hagerty

O.W. Taylor

(1)

(1)

\section{LIBRARIES}

RSL

TIC

WAMO

\section{$E G \& G / E M$}

(25)

OSTI
(1)

(1)

J. F. Doyle LVAO (1)

G. R. Shipman WAMO (1)

W. J. Tipton LVAO (1)

R. J. Vojtech WAMO (1)

P. H. Zavattaro LVAO (1)

(30)

(1)

AN AERIAL RADIOLOGICAL SURVEY OF THE NEUTRON PRODUCTS COMPANY AND SURROUNDING AREA

DICKERSON, MARYLAND EGG 11265-1081

DATE OF SURVEY: NOVEMBER 1993 DATE OF REPORT: DECEMBER 1994 